\title{
A Feasibility Study of Mobile Phone Casings Remanufacturing
}

\author{
Shu-San Gan ${ }^{1}$, Juliana Anggono ${ }^{1 *}$, Didik Wahjudi ${ }^{1}$, Yopi Tanoto $^{1}$, Randy $^{1}$ and \\ Novana Hutasoit $^{2}$ \\ ${ }^{1}$ Mechanical Engineering Department, Petra Christian University, Surabaya, Indonesia \\ ${ }^{2}$ Mechanical and Product Design Engineering Department, Swinburne University of Technology, \\ Hawthorn, Australia
}

\begin{abstract}
Remanufacturing is a process when used product or core is brought to 'like-new' condition, might be with an upgrade in performance. This process complies with technical specifications, including engineering, quality, and testing standards. It yields a fully warranted product. The purpose of this study was to conduct initial research on the feasibility of remanufacturing primarily on the mobile phone casings to provide information and consideration for a firm that would do remanufacturing of mobile phones. A series of material characterization on several mobile phone casings manufactured by major international brands revealed that remanufacturing is not a viable route to attempt. The evaluation shows that remanufacturing used casing mobile phone require several stages of repair, which cause an increase in the cost that can, in turn, affect the prices.
\end{abstract}

Keywords: Casing material, electronic goods, material characterization, recovery process.

\section{Introduction}

Rapid development in mobile phone technology during the last decade has resulted in the availability of various brands and specifications of mobile phones in the market. The growing dependence on smartphones as well as the availability of brands offering higher specification devices at an affordable price has triggered a faster upgrade cycle or in other words, reducing the smartphone replacement cycle. Furthermore, the number of discarded mobile phones increases significantly, either from damaged mobile phones or merely outdated models, which will become electronic wastes or e-waste, e-waste reaches $41.8 \times$ $10^{9} \mathrm{~kg}$ in the world consisting of $1 \times 10^{9} \mathrm{~kg}$ of waste lamps, $3 \times 10^{9} \mathrm{~kg}$ of small electronic goods waste, $6.3 \times 10^{9} \mathrm{~kg}$ of electronic display, $7 \times 10^{9} \mathrm{~kg}$ of temperature control waste, $11.8 \times 10^{9} \mathrm{~kg}$ of large electronic equipment waste and $12.8 \times 10^{9} \mathrm{~kg}$ of small electronic equipment [1]. The mobile phone categorized as small electronic goods. Therefore, one way to overcome that waste problem is by performing remanufacturing.

Remanufacturing is a process when an old product or core is made like a new condition, even upgrade in better performance [2-4]. This process complies with technical specifications, including engineering, quality, and testing standards. It produces a product

${ }^{*}$ Corresponding author : julianaa@petra.ac.id 
that provides a similar guarantee to the new one. Remanufacturing is one among many recovery processes that are able to reduce the amount of waste by recovering products or components back to their usage stage, which consequently extends the products' life. Recently, remanufacturing activities are intended for products that have a very high price and have a reasonable component size to be remanufactured [4]. Remanufacturing is a promising recovery process for electronic products and mobile phones [5-7]. Other studies showed that it was profitable [8-10]. In this research, remanufacturing was focused on mobile phone casings, where a feasibility study was conducted to identify the possibility of remanufacturing mobile phone casings. Mobile phone casing refers to the phone's frame and back casing. The physical damage of a mobile phone is mostly found in the outer casing due to the effects of abrasion, impact and other deformation acts, which are affected by the strength of mobile phone casings materials used.

\section{Methodology}

There are three types of materials that commonly used for mobile phone casings in Indonesia, which are an aluminum alloy, plastic, and glass. This study was conducted in two phases: (i) an interview process with a mobile phone manufacturer and several mobile phone users to understand their view on the possibility of doing mobile phone remanufacturing, (ii) material characterization using Scanning Electron Microscopy (SEM) and Energy Dispersive X-Ray Analysis (EDAX) to analyze the structure of casing materials casings including their manufacturing process. The results show that the mobile phone is not suitable for remanufacturing, based on material analysis, process difficulty, as well as cost projection.

The mobile phones which used for materials characterization were selected from three different brands representing brands from Unites States (Apple), South Korea (Samsung), and China (Redmi). Those three brands had their casings made from aluminum alloy, plastics, and glass (Table 1).

Table 1. Mobile phone selection for material characterization.

\begin{tabular}{ccc}
\hline Brand & Model & Casing material \\
\hline Apple & iPhone 5 & Aluminum \\
Xiaomi & Redmi 3 & Aluminum \\
Samsung & Galaxy S5 & Plastic \\
Samsung & Galaxy S6 & Glass \\
\hline
\end{tabular}

Study of the material structure and composition of the phone casings was conducted using SEM and EDAX analysis for iPhone, Redmi, and Samsung S5. Meanwhile, for phone casings made from glass (Galaxy S6), a literature study from Corning's Gorilla glass was used as a reference. Upon completing the characterization and obtaining information from interviews with national smartphone manufacturer and users, those results were analyzed to provide some recommendations for remanufacturing.

\section{Results and discussion}

Evaluation with SEM and EDAX was performed on the back cover section at three different locations, i.e., at the top surface, cross-sectional area, and the bottom surface of each evaluated casing piece. The materials evaluated were aluminum alloy (iPhone 5 and Xiaomi Redmi 3) and plastic (Samsung Galaxy S5). 


\subsection{Plastic: Samsung Galaxy S5}

Figure 1 shows SEM images at three different regions in the observed sample of Samsung Galaxy S5 casing. The areas studied were the top surface, bottom surface, and crosssectional area. Figure 1(c) shows that this casing made from plastic material with a minimum thickness of $623.6 \times 10^{-6} \mathrm{~m}$ and maximum to $636.4 \times 10^{-6} \mathrm{~m}$. There was no coating applied to this plastic casing. Chemical composition tests with EDAX confirmed that, this plastic material in which their major constituent elements are mainly carbon and oxygen, as shown in Table 2. The type of plastic is polycarbonate, which manifests high strength and toughness; therefore, do not scratch, deform, and crack easily [11]. Plastic is also lighter, compared to the metal casing and does not conduct heat well. Therefore, there is no cold feeling when holding it. Polycarbonates much cheaper to form and mold than metal or glass.

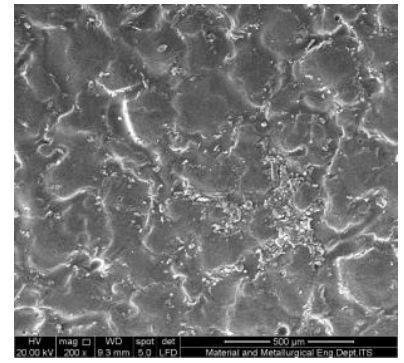

(a)

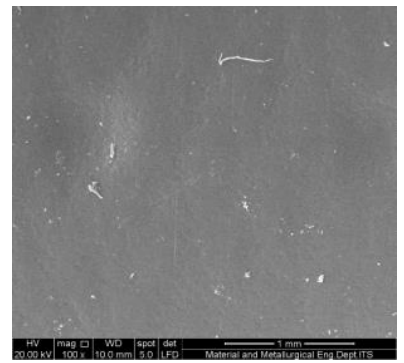

(b)

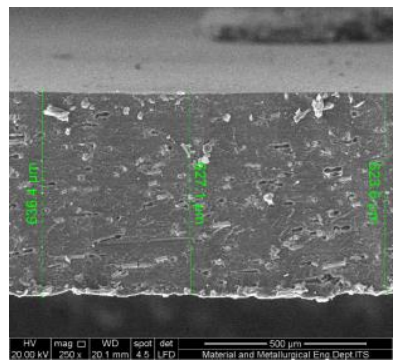

(c)

Fig. 1. SEM micrographs of material casing of Samsung Galaxy S5 (a) top surface, (b) bottom surface and (c) cross sectional area.

Table 2. Chemical composition of plastic material in Samsung Galaxy S6.

\begin{tabular}{cccc}
\hline \multirow{2}{*}{ Casing section } & \multicolumn{3}{c}{ \% Weight } \\
\cline { 2 - 4 } & Carbon & Oxygen & Magnesium \\
\hline Top & 58.02 & 29.67 & - \\
Bottom & 63.96 & 28.84 & - \\
Cross section & 55.55 & 34.65 & - \\
\hline
\end{tabular}

\subsection{Aluminum: Apple iPhone 5 and Xiaomi Redmi 3}

SEM studies observed that this Xiaomi Redmi 3 consisted of aluminum alloy casing with a coating layer adhered to it with a minimum thickness of $8.218 \times 10^{-6} \mathrm{~m}$ to a maximum of $8.975 \times 10^{-6} \mathrm{~m}$ (Fig. 2 b) or nearly twice the coating layer thickness identified on iPhone 5 (Fig. 2a). 


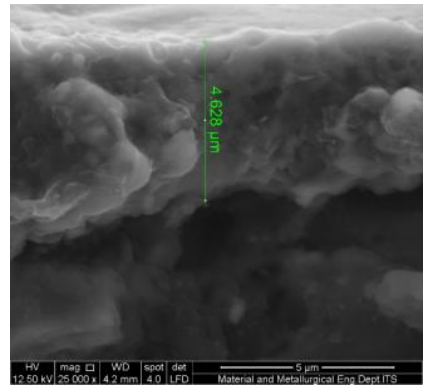

(a) iPhone 5

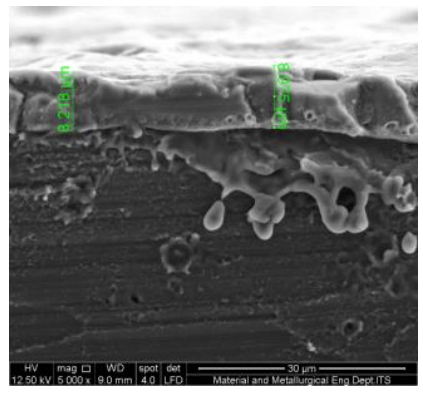

(b) Xiaomi Redmi 3

Fig. 2. SEM micrographs of cross-sectional of aluminum casings.

The Apple phone used aluminum alloy 7000 series that was stated as its Apple's Patent Pending. This type of alloys has high yield strength such that the alloys do not dent easily [12]. Table 3 explains that the amount of oxygen in iPhone 5 is significantly high due to the anodizing process for its coating, while in Redmi 3, it uses spraying for coloring.

Table 3. Chemical composition of aluminium alloy in iPhone 5 and Redmi 3.

\begin{tabular}{|c|c|c|c|c|c|c|c|c|}
\hline \multirow{2}{*}{$\begin{array}{c}\text { Casing } \\
\text { Horizontal }\end{array}$} & \multicolumn{8}{|c|}{ \% Weight } \\
\hline & $\mathrm{C}$ & $\mathbf{O}$ & Mg & Al & $\mathbf{S i}$ & $\mathbf{S}$ & $\mathbf{K}$ & $\mathbf{C a}$ \\
\hline iPhone 5 & 31.66 & 1.07 & 1.37 & 35.02 & 24.76 & 1.46 & 1.78 & 2.87 \\
\hline Redmi 3 & 8.55 & -- & 2.35 & 68.73 & 1.22 & 1.51 & -- & -- \\
\hline
\end{tabular}

\subsection{Glass: Samsung Galaxy S6}

Samsung Galaxy S6 used Gorilla glass 4, which introduced in November 2014. Until the present time, Corning has marketed Gorilla Glass 6 (has a compressive strength due to the chemically strengthened surface produced through new glass composition compared with Gorilla Glass 5) which was introduced on 18 July 2018 and twice better than Gorilla Glass $5[13,14]$. Most mobile phone companies that use glass material for the casing use Corning Gorilla Glass. In this research, the studied mobile phones were within the age of two to five years. Therefore the gorilla glasses that were discussed in this section were of serie 4 and serie 5.

From the reference provided by Corning Inc [14-15], it appears that Gorilla Glass 6 has the highest durable level compared to the previous series as described in Figure 3 [13].

A pendulum and an emery paper of 180 use for drop test (Figure 3a). The glass attached to the pendulum will be dropped from a certain distance and hit the emery paper of 180 . The damage resistance of Gorilla Glass 5 increases by 1.5 up to 1.8 times compared to glass 4. The glass thickness parameter is set from 0.4 to 0.8 because there are differences in thickness produced by Corning for Gorilla Glass 4 and Gorilla Glass 5. As in Figure 3(b) it can be seen that Gorilla Glass 5 is able to withstand $10 \%$ more scratches in the pressure of $3462.1224075 \mathrm{~Pa}$ and $65 \%$ more in $6231.8203335 \mathrm{~Pa}$ pressure compared to Gorilla Glass 4. 


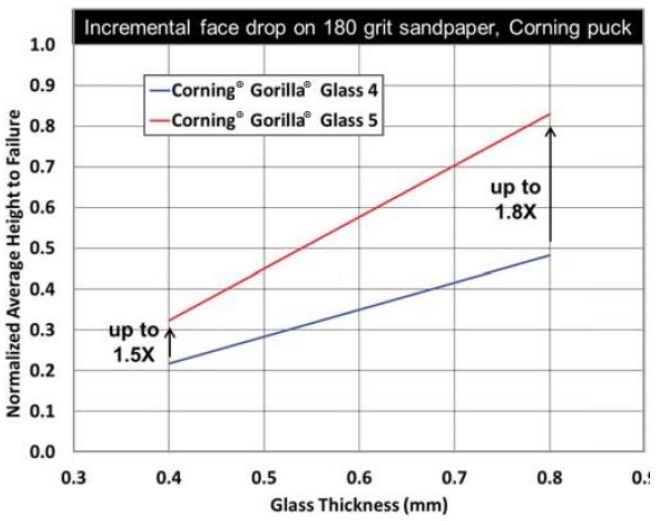

(a) drop test through incremental face drop on 180 grit sandpaper

Fig. 3. Glass material characterization $[14,15]$.

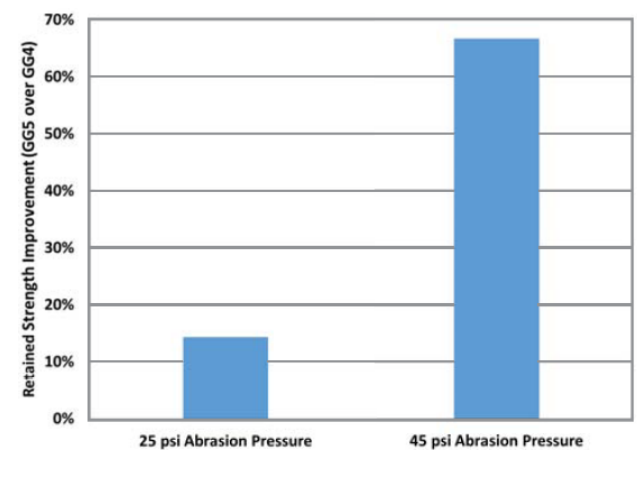

(b) scratch test

\section{Analysis}

The analysis was performed to evaluate their material structures, including the presence of the coating layer as well as their composition. Their construction will dictate the required process to remanufacture the phone casings to 'like-new' condition. The SEM observations in section 3 show that not all phone casings provide coating as a protection layer, as summarized in Table 4.

Table 4. Coating identification on mobile phone casing.

\begin{tabular}{ccccc}
\hline Brand & Model & $\begin{array}{c}\text { Casing } \\
\text { material }\end{array}$ & Coating & Thickness (m) \\
\hline Apple & iPhone 5 & Aluminum alloy & yes & $4628 \times 10^{-6}$ \\
Xiaomi & Redmi 3 & Aluminum alloy & yes & $8218 \times 10^{-6}$ to \\
& Galaxy S5 & Polycarbonate & no & -- \\
Samsung & Galaxy S6 & Gorilla glass 4 & no & -- \\
Samsung & & & &
\end{tabular}

In the case of physical damage on the coating part, the process of recovering it would take two stages, i.e., first is removing the coating, and the next part is applying the new one. However, those stages are not simple tasks because the remanufacturer should provide labors and materials. Furthermore, the thickness of the coating should be consistent with a certain tolerance to ensure the compatibility with the external accessories casing, which increases the complexity of the process. Cost projection for those processes of cleaning and reconditioning is considerably high. As for the plastic casing, it is not feasible to recover the phone casing since replacing the damaged casing with the new casing would be much cheaper and manageable. Therefore, recovering or reconditioning plastic phone casing is not an option. As with glass casing, the literature study shows that it is not possible to recover a damaged glass phone class since the process of manufacturing the casing can not be made partially. However, considering the improvement in the latest series of gorilla glass, it seems that the probability of reusing the glass phone casing series 5 is high. It is most likely that the gorilla glass is still in good condition when the product collected for 
remanufacturing. Therefore, a remanufacturing is only possible when the glass casing even in good condition, with no deep scratch or cracks.

The analysis shows that the remanufacturing of mobile phone casing is very limited. However, it does not mean that remanufacturing a mobile phone is not possible. It can be conducted when the other parts of the mobile phone are recoverable, as follows:

(i) Plastic casing: a new one can replace the casing with low cost

(ii) Aluminum casing: the phone casing can be remanufactured when the physical damage is minimal and can be recovered by a thin coating

(iii) Glass casing: the phone casing can be remanufactured when it is in good condition.

\section{Conclusion}

In carrying out remanufacturing casing for mobile phones, it is necessary to study its materials structure, composition, and damaged condition. Mobile phone casings from plastic, mainly made from polycarbonate and are varied in their texture, color, and thickness from one brand to another depending on the design and price setting. As with mobile phones using glass materials for their casings, their casings are mainly made of Corning Gorilla glass. It is concluded that mobile phone casings are not suitable for remanufacturing due to the required remanufacturing work will be needed several stages of repair. As a result, the cost of remanufacturing may surpass the price of new casings available in the market. Therefore, it makes remanufacturing become impractical to implement. However, considering the current practices by Apple and a refurbishing company in Malaysia, it is possible to recover the mobile phone under refurbishment. Therefore, it initiates research toward improving the feasibility of refurbished mobile phone casings through material characterization.

\section{References}

1. C. Baldé, F. Wang, R. Kuehr, J. Huisman. The Global E-Waste Monitor 2014. Bonn: United Nations University (2015). p.8-24

https://i.unu.edu/media/unu.edu/news/52624/UNU-1stGlobal-E-Waste-Monitor-2014small.pdf

2. R.T. Lund, W.M. Hauser. Remanufacturing - An american perspective. Proceeding of $5^{\text {th }}$ International Conference on Responsive Manufacturing - Green Manufacturing, (Ningbo, China, 2010). ICRM, 2010:1-6(2010)

https://ieeexplore.ieee.org/document/5629156

3. M. Charter, C. Gray. Int. J. Prod. Dev, 6,3-4:375-392(2008). https://www.researchgate.net/publication/247834190 Remanufacturing and product design

4. A. Ikeda. Remanufacturing of automotive parts in Japanese market. The $24^{\text {th }}$ CIRP Conference on Life Cycle Engineering, (Kamakura, Japan 2017). Procedia CIRP 61: 800-803(2017).

5. C. Franke, B. Basdere, M. Ciupek, S. Seliger. Omega, 34,6:562-570(2006). https://econpapers.repec.org/article/eeejomega/v_3a34_3ay 3a2006_3ai_3a6 3ap 3a 562-570.htm

6. B. Tong. Research on the cell phone remanufacturing and reselling. [Thesis] Erasmus University Rotterdam (2006). p.18-42

https://www.maritimeeconomics.com/research/mel-thesis-library/ 
7. P. Rathore, S. Kota, A. Chakrabarti. J. Clean. Prod, 19,15:1709-1722(2011). https://www.sciencedirect.com/science/article/pii/S0959652611002277

8. J. Quariguasi-Frota-Neto, J. Bloemhof, Production and Operations Management, 21,1:101-114(2012). https://onlinelibrary.wiley.com/doi/abs/10.1111/j.1937-5956.2011.01234.x

9. K. Xing, M. Belusko, L. Luong, K. Abhary. Int. J. Adv. Manuf. Tech, 35,1:114(2007). https://link.springer.com/article/10.1007/s00170-006-0698-9

10. M. Kwak, H. Kim. J. Mech. Design, 135,1:1-10(2013).

http://mechanicaldesign.asmedigitalcollection.asme.org/article.aspx?articleID=167469 $\underline{7}$

11. J. Ho. A discussion on material choices in mobile [Online] from https://www.anandtech.com/show/7984/discussion-on-material-choices-in-mobile (2014) [Accessed on 23 February 2019].

12. J. Purcher. Apple's Patent Pending 7000 Series Aluminum Invention used in the new iPhone 6s comes to Light [Online] from https://www.patentlyapple.com/patentlyapple/2015/12/apples-patent-pending-7000-series-aluminum-invention-used-in-thenew-iphone-6s-comes-to-light.html (2015) [Accessed on 23 February 2019].

13. Corning Inc. Corning Gorilla Glass 6. [Online] from https://www.corning.com/content/dam/corning/microsites/csm/gorillaglass/PI Sheets/ Corning Gorilla Glass 6 PI Sheet.pdf (2018) [Accessed on 23 February 2019].

14. Corning Inc. Corning Gorilla Glass 5. [Online] from https://www.corning.com/content/dam/corning/microsites/csm/gorillaglass/PI Sheets/ Corning\%20Gorilla\%20Glass\%205 PI\%20Sheet Rev C.pdf (2018) [Accessed on 21 May 2018].

15. Corning Inc. Corning Gorilla Glass 4. [Online] from https://www.corning.com/content/dam/corning/microsites/csm/gorillaglass/PI Sheets/ CGG PI Sheet Gorilla\%20Glass\%204.pdf (2015) [Accessed on 21 May 2018] 